\title{
ANALISIS KOMPARASI PERFORMA JARINGAN KOMPUTER PADA IMPLEMENTASI IPv4 dan IPv6
}

\author{
Ahmad Tantoni ${ }^{1}$, Mohammad Taufan Asri Zaen ${ }^{2}$ Sofiansyah Fadli ${ }^{3}$ \\ 1,2,3 Teknik Informatika, STMIK Lombok \\ Jln. Basuki Rahmat No.105 Praya Lombok Tengah 83511 \\ ${ }^{1}$ ahmad.tantoni@students.amikom.ac.id, ${ }^{2}$ opanzain@gmail.com, ${ }^{3}$ sofiansyah182@gmail.com
}

\begin{abstract}
Routers have important functions in the network, especially the internet. Routers can connect several network segments so that they can communicate with other users even though they are separated by a great distance (Sofana, 2013). IPv4 was originally a 32-bit binary number that was used to identify hosts on the network, after successful use by internet users then a new problem arises where IPv4 cannot accommodate Internet users in the future because it runs out of IPv4 addresses. Then IPv6 was created with the aim to provide more addressing than IPv4 (Sugeng, 2015). The problem is seen from the difference in the bit width between IPv4 and IPv6 whether it affects the CPU performance of the computer and the performance of data sent, average speed on the network. Then there will be research on the comparative performance of the CPU load and the performance of the data sent, the average speed of the computer network on the implementation of IPv4 and IPv6 using Passmark Advance Network Test. So that it can provide an overview of the results of the comparison of IPv4 and IPv6 QoS that are better than the 3 parameters tested with TCP and UDP protocols.
\end{abstract}

Keywords : Comparative Analysis, Network Performance, Computer Networks, Ipv4, Ipv6

\begin{abstract}
Abstrak
Router memiliki fungsi yang cukup penting dalam jaringan, terutama internet. Router dapat menghubungkan beberapa segmen jaringan sehingga dapat berkomunikasi dengan pengguna lain meskipun dipisahkan oleh jarak yang sangat jauh (Sofana, 2013). IPv4 pada awalnya adalah sederetan bilangan biner sepanjang 32 bit yang dipakai untuk mengidentifikasi host pada jaringan, setelah sukses penggunaannya oleh para pengguna internet kemudian timbul masalah baru dimana IPv4 tidak dapat menampung para pengguna internet dimasa depan karena kehabisan alamat IPv4. Kemudian diciptakan IPv6 dengan tujuan untuk memberi pengalamatan yang lebih banyak dibandingkan dengan IPv4 (Sugeng, 2015). Permasalahan dilihat dari perbedaan besaran lebar bit-nya antara IPv4 dengan IPv6 apakah berpengaruh terhadap kinerja komputer CPU load dan performa data sent, average speed pada jaringan tersebut. Maka akan dilakukan penelitian mengenai komparasi kinerja komputer CPU load dan performa data sent, average speed jaringan komputer pada implementasi IPv4 dan IPv6 menggunakan software Passmark Advance Network Test. Sehingga dapat memberikan gambaran hasil komparasi QoS IPv4 dan IPv6 yang lebih baik dari 3 parameter yang diujikan dengan protocol TCP dan UDP.
\end{abstract}

Kata kunci : Analisis Komparasi, Performa Jaringan, Jaringan Komputer, Ipv4, Ipv6

\section{Pendahuluan}

Kebutuhan akan informasi saat ini sangat cepat, dibuktikan dengan semua serba online di kalangan pemerintah ataupun swasta dan perusahaan ataupun perorangan, hal ini dikarenakan karna semakin banyaknya yang menggunakan layanan internet untuk

ISSN. 2620-6900 (Online) 2620-6897 (Cetak) 
berkomunikasi. Akibat pertumbuhan pengguna layanan internet ini membuat semakin meningkatnya lalu lintas trafik data pada dunia internet menjadi semakin ramai. Suatu Router harus mampu dalam melakukan proses routing untuk dapat menentukan jalan tercepat atau terdekat dalam mengalirkan paket-paket data agar sampai tepat pada tujuannya. (Ulfa dan Fatoni, 2017)

Router memiliki fungsi yang cukup penting dalam jaringan, terutama internet. Router dapat menghubungkan beberapa segmen jaringan sehingga dapat berkomunikasi dengan pengguna lain meskipun dipisahkan oleh jarak yang sangat jauh (Sofana, 2013). Router bekerja dengan cara menentukan jalur yang akan dipilih untuk mengirimkan paket-paket data dari sumber ketujuan. Proses pencarian dan penentuan jalur inilah yang disebut dengan routing, sedangkan salah satu komponen terpenting pada network TCP/IP, protocol routing secara dinamis berkomunikasi untuk menentukan rute terbaik mencapai tujuan. Paket di-forward dari satu Router ke Router yang lain. (Sofana, 2012)

IPv4 pada awalnya adalah sederatan bilangan biner sepanjang 32 bit yang dipakai untuk mengidentifikasi host pada jaringan, setelah sukses penggunaannya oleh para pengguna internet kemudian timbul masalah baru dimana IPv4 tidak dapat menampung para pengguna internet dimasa depan karena kehabisan alamat IPv4. Kemudian diciptakan IPv6 dengan tujuan untuk memberi pengalamatan yang lebih banyak dibandingkan dengan IPv4. (Sugeng, 2015)

Permasalahan dilihat dari perbedaan besaran lebar bit-nya antara IPv4 dengan IPv6 apakah berpengaruh terhadap kinerja komputer CPU load dan performa data sent, average speed pada jaringan tersebut.

Dari latar belakang ini maka akan dilakukan penelitian mengenai komparasi kinerja komputer CPU load dan performa data sent, average speed jaringan komputer pada implementasi IPv4 dan IPv6 menggunakan software Passmark Advance Network Test. Sehingga dapat memberikan gambaran hasil komparasi QoS IPv4 dan IPv6 yang lebih baik dari 3 parameter yang diujikan dengan protocol TCP dan UDP.

\section{Tinjuan Pustaka}

Putra, SAP., dalam penelitiannya Analisis Komparasi QoS IPv4 dan IPv6 pada Topologi Jaringan Komputer di Lab CTC FTI-UKSW. Penelitian ini berfokus pada perbandingan analisis QoS IPv4 dan IPv6 dengan parameter delay, throughput dan packet loss untuk menentukan baik atau buruknya suatu jaringan komputer. Persamaan yang sudah dibahas penelitian menggunakan PPDIOO method dalam pengembangannya. Perbedaan penelitian adalah berbeda salam menggunakan parameter. penelitian ini menggunakan parameter kinerja komputer CPU load dan performa data sent, average speed dengan software Passmark Advance Network Test, perbedaan yang lain juga adalah penelitian sebelumnya pengujian routing sedangkan penelitian yang dilakukan mengguji keandalan jaringan client server dalam dan tidak menguji performa routing IPv4 dan IPv6.

Ulfa, Maria dan Fatoni., dalam penelitiannya Analisis Perbandingan Penerapan Static Routing Pada IPv4 dan IPv6 pada Universitas Bina Darma. Penelitian ini dengan dasar semakin menipisnya IPv4 dan diimplementasinya IPv6, kemudian penelitian lebih berfokus pada perbandingan static routing pada IPv4 dan IPv6 dengan parameter throughput, delay dan packet loss. Penggunaan router yang digunakan pada penelitian sebelumnya 5 router dengan konfigurasi routing static. Perbedaan penelitian pada metodologi penelitian menggunakan penelitan tindakan atau experimental research. penelitian ini menggunakan parameter kinerja komputer CPU load dan performa data sent, average speed dengan software Passmark Advance Network Test. Penelitian ini menggunakan PPDIO0 method dalam metodologi penelitian. Perbedaan penelitian yang lain juga, penelitian sebelumnya pengujian routing sedangkan penelitian yang dilakukan mengguji keandalan jaringan client server dalam dan tidak menguji performa routing IPv4 dan IPv6.

Rahmiati, P,; Aryanta, D,; Priyadi, TA., dalam penelitiannya Perancangan dan Analisis Perbandingan Implementasi OSPF pada Jaringan IPv4 dan IPv6. Penelitian ini lebih berfokus pada perbandingan routing OSPF pada IPv4 dan IPv6 dengan parameter nilai delay, trace route dan waktu konvergensinya antara OSPF IPv4 dan IPv6. Penelitian ini menggunakan simulasi cisco packet tracer dengan penggunaan perangkat jaringan yang digunakan pada penelitian sebelumnya sebanyak 8 buah router, 10 buah PC dan 5 buah switch. Perbedaan penelitian pada metodologi penelitian menggunakan experimental research. Perbedaan yang lain menggunakan parameter kinerja komputer CPU load dan performa data sent, average speed dengan software Passmark Advance Network Test. Tidak hanya itu, perbedaan penelitian ini 
juga pada metodologi penelitian menggunakan PPDIOO method. Perbedaan penelitian yang lain juga, penelitian sebelumnya pengujian routing sedangkan penelitian yang dilakukan mengguji keandalan jaringan client server dalam dan tidak menguji performa routing IPv4 dan IPv6.

Paramayudha, G R., dalam penelitiannya Analisis Perbandingan Performansi Jaringan IPv6 dan Tunneling 6T04 Untuk Aplikasi File Transfer Protocol (FTP) Pada Media Wired dan Wireless Disisi Client. Penelitian ini berfokus pada mekaisme transisi untuk mengganti pengguna jaringan IPv4 menjadi jaringan IPv6 secara keseluruhan dengan teknik Tunneling 6T04 dengan protokol yang digunakan untuk menguji Aplikasi File Transfer Protocol (FTP) untuk kebutuhan proses download dan upload salam satu server dalam media wired dan wireless di sisi client. Penelitian ini masih dalam bentuk simulasi menggunakan GNS3 sebagai emulator dengan parameter pengujian kualitas jaringan meliputi tranfer time, througput dan delay. Perbedaan penelitian pada metodologi penelitian ini menggunakan experimental research, sedangkan penelitian selanjunya PPDIOO method. Perbedaan yang lain menggunakan parameter kinerja komputer CPU load dan performa data sent, average speed dengan software Passmark Advance Network Test. Tidak hanya itu, perbedaan penelitian sebelumnya pengujian tunelling 6TO4 dengan protocol FTP IPv4 dan IPv6 sedangkan penelitian yang dilakukan mengguji keandalan jaringan client server dalam dan tidak menguji performa routing IPv4 dan IPv6.

\subsection{Pengertian Jaringan Komputer}

jaringan komputer merupakan komputer yang sekurangkurangnya terdiri dari dua unit komputer atau lebih, dapat berjumlah puluhan komputer, ribuan atau bahkan jutaan node yang saling terhubung satu sama lain. Di dalam jaringan komputer dikenal sistem koneksi antarnode (komputer). (Ariyus dan Andri, 2008)

\subsection{Internet Protocol Address (Alamat IP)}

Internet Protocol Address atau alamat IP yang bahasa awamnya bisa disebut dengan kode pengenal komputer pada jaringan. Yang merupakan kode vital dalam dunia internet. Karena alamat IP dapat dikatakan sebagai identitas dari pemakai internet, sehingga antara satu alamat dengan alamat lainnya tidak boleh sama. Internet protocol (IP) pada awalnya dirancang untuk memfasilitasi hubungan antara beberapa organisasi yang tergabung dalam departemen pertahanan amerika yaitu Advanced Research Project Agency (ARPA). Sebelum terciptanya internet protocol, jaringan memiliki peralatan dan protocol tersendiri yang digunakan untuk saling berhubungan. Kemudian dibuatlah suatu protocol yang dapat dapat digunakan secara umum untuk menyatukan berbagai perbedaan dalam penggunaan perangkat yang terhubung didalam jaringan. Protocol tersebutlah yang sampai saat ini masih mendominasi dalam pemakaiannya oleh masyarakat banyak yaitu Internet Protocol version 4 (IPv4). (Sugeng,2006)

\subsection{Internet Protocol Version $4(\operatorname{IPv} 4)$}

Alamat IP (IPv4) pada awalnya adalah sederet bilangan biner sepanjang 32 bit yang dipakai untuk mengidentifikasikan host pada jaringan. Alamat IP ini diberikan secara unik pada masing-masing komputer/host yang terhubung ke in nternet. Prinsip kerjanya adalah packet yang membawa data dimuati alamat IP dari komputer pengirim data kepada alamat IP pada komputer yang akan dituju, kemudian data tersebut dikirim ke jaringan. Packet ini kemudian dikirim dari router ke router dengan berpedoman pada alamat IP tersebut menuju ke komputer yang dituju. Seluruh komputer / host yang tersambung ke internet, dibedakan hanya berdasarkan alamat IP ini, oleh karena itu tidak boleh terjadi duplikasi pada alamat IP untuk setiap komputer yang terhubung ke jaringan internet (Sugeng, 2006).

Alamat-alamat IP panjangnya 32 bit dan dibagi menjadi dua identifikasi sebagai berikut (Yani, 2006):

a. Bagian identifikasi net ID menunjukkan identitas jaringan komputer tempat hosthost (komputer) dihubungkan.

b. Bagian identifikasi host ID memberikan suatu pengenal unik pada setiap host (komputer) pada suatu jaringan komputer

\subsection{Internet Protocol Version 6 (IPv6)}

Internet Protocol version 6 (IPv6) atau yang sering disebut juga sebagai IPng (Internet Protocol next generation) adalah suatu protocol layer ketiga terbaru yang diciptakan untuk menggantikan IPv4 atau yang sering dikenal sebagai IP. Alasan utama dari penciptaan Internet Protocol version 6 (IPv6) ini adalah untuk mengoreksi masalah pengalamatan pada versi 4 (IPv4). Karena kebutuhan akan alamat internet semakin banyak, maka IPv6 diciptakan dengan tujuan untuk memberikan pengalamatan yang lebih banyak dibandingkan dengan IPv4, sehingga perubahan pada IPv6 masih 
berhubungan dengan pengalamatan IP sebelumnya. Konsep pengalamatan pada IPv6 memiliki persamaan pada IPv4, akan tetapi lebih diperluas dengan tujuan untuk menciptakan sistem pengalamatan yang bisa mendukung perkembangan internet yang semakin pesat dan penggunaan aplikasi baru di masa depan. Perubahan terbesar pada IPv6 adalah terdapat pada header, yaitu peningkatan jumlah alamat dari 32 bit (IPv4) menjadi 128 bit (IPv6). (Sugeng, 2006).

Protokol IPv6 menyediakan ruang alamat sebesar 128 bit yaitu 4 kali lipat ruang alamat yang disediakan IPv4. Format alamat yang ada pun berbeda dengan format alamat pada IPv4. Berbeda dengan IPv4, IPv6 yang disediakan sebagai pengenal pada 1 atau lebih interface dibedakan atas 3 tipe yaitu (Wicaksono, 2002):

a. Unicast address : pengenal untuk 1 Network Interface Card, dimana paket data yang dikirim ke unicast address hanya dikirim ke Network Interface Card yang bersangkutan saja.

b. Anycast address : pengenal untuk beberapa Network Interface Card sekaligus, dimana paket data yang dikirim ke anycast address akan dikirim ke salah satu Network Interface Card.

c. Multicast address : pengenal untuk beberapa Network Interface Card sekaligus, dimana paket data yang dikirim ke multicast address akan dikirim ke semua Network Interface Card yang bersangkutan.

\section{Metodologi Penelitian}

Metodologi penelitian yang digunakan adalah PPDIO0 Method. Penjelasan dari masingmasing tahapan PPDIOO (Teare, 2008), sebagai berikut:

a. Prepare (Persiapan). Melibatkan penerapan persyaratan organisasi (bisnis), mengembangkan startegi jaringan, mengusulkan arsitektur jaringan konseptual tingkat tinggi dan mengindentifikasi teknologi terbaik yang dapat mendukung arsitektur jaringan.

b. Plan (Rencanakan). Melibatkan identifikasi kebutuhan jaringan awal berdasarkan tujuan, fasilitas, kebutuhan pengguna, kebutuhan hardware/software dan sebagainya. Tahap rencana melibatkan karakteristik situs dan menilai jaringan yang ada dan melakukan analisis untuk menentukan apakah infrastruktur yang ada sistem dan lingkungan operasional dapat mendukung sistem yang diusulkan.

c. Design (Perancangan). Persyaratan awal yang tentukan dalam tahapan perencanaan mendorong kegiatan spesialis desain jaringan. Spesifikasi desain jaringan yang dihasilkan adalah desain rinci komprehensif yang memenuhi kebutuhan bisnis saat ini dan kebutuhan teknis lalu menggabungkan spesifikasi untuk mendukung ketersediaan, keandalan, keamanan, skalabilitas dan kinerja.

d. Implement (Pelaksanaan). Jaringan yang dibangun atau komponen tambahan lainnya dimasukkan sesuai dengan spesifikasi desain dengan tujuan mengintegrasikan perangkat tanpa menggangu jaringan yang ada atau membuat titik kerentanan.

e. Operate (Pengoperasian \& Evaluasi). Merupakan tujuan akhir dari kesesuaian desain yang sudah rancang. Tahapan operasional melibatkan pemeliharaan/menjaga jaringan komputer melalui kegiatan pada setiap harinya, termasuk menjaga ketersediaan jaringan yang tinggi dan mengurangi biaya.

f. Optimize. Melibatkan manajemen jaringan yang proaktif. Tujuan dari manajemen proaktif adalah untuk mengidentifikasi dan menyelesaikan masalah sebelum masalah nyata muncul dan dapat mempengaruhi organisasi. Deteksi dan koreksi kesalahan relatif (troubleshooting) dibutuhkan ketika manajemen proaktif tidak dapat memprediksi dan mengurangi kegagalan.

\section{Hasil dan Pembahasan}

Hasil pengujian komparasi kinerja komputer CPU load dan performa data sent, average speed jaringan komputer pada implementasi IPv4 dan IPv6 menggunakan software Passmark Advance Network Test dengan protocol TCP dan UDP, sebagai berikut:

\subsection{Desain topologi jaringan}

Desain topologi jaringan IPv4 dan IPv6 pada gambar dibawah sebagai berikut: 


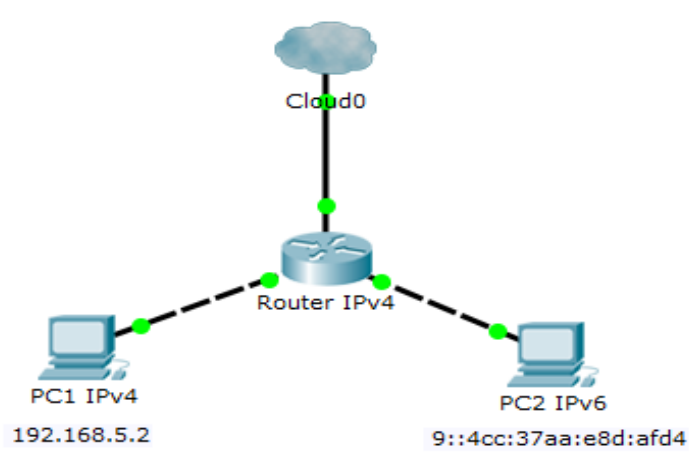

Gambar 4.1 Desain Topologi Jaringan IPv4 dan IPv6

Pada gambar 4.1 menunjukan Desain topologi jaringan IPv4 dan IPv6, dalam melakukan pengujian dilakukan secara bergantian. Melakukan pengujian IPv4 terlebih dahulu dilakukan dan setelah itu pengujian IPv6 dilakukan pada masing-masing protocol TCP dan UDP

4.2 Pengujian performa IPv4 pada protocol TCP dan UTP

Pengujian performa IPv4 protocol TCP dan UTP pada gambar dibawah, sebagai berikut:

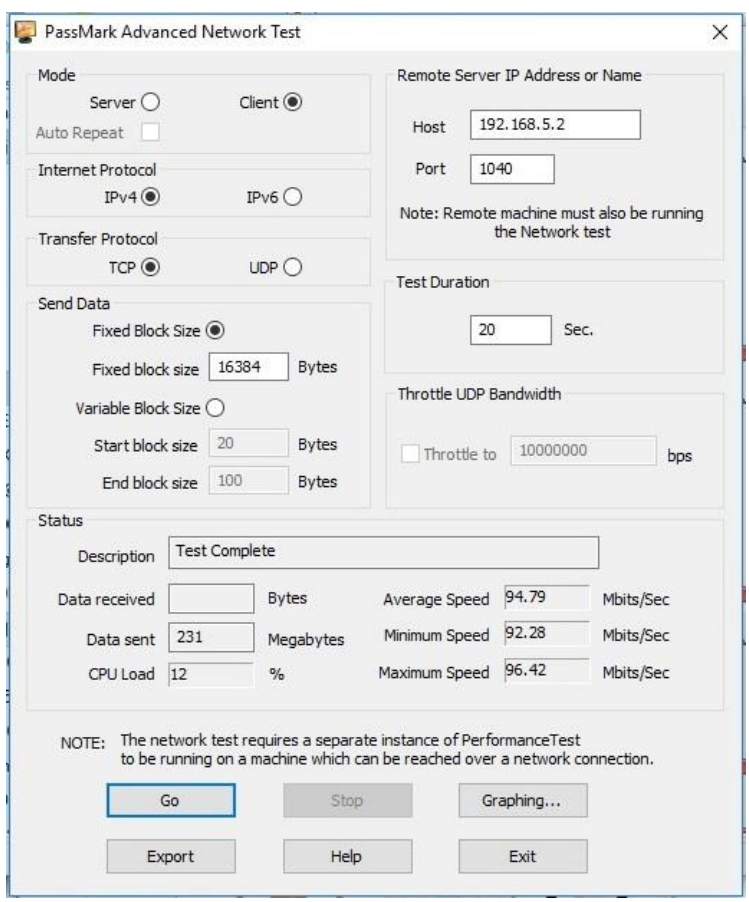

Gambar 4.2 Hasil Pengujian IPv4 dengan Protocol TCP

Gambar 4.2 menunjukan hasil pengujian IPv4 menggunakan protocol TCP dengan mode client dan durasi pengujian 20 detik dan hasil sapat dilihat pada kolom status.

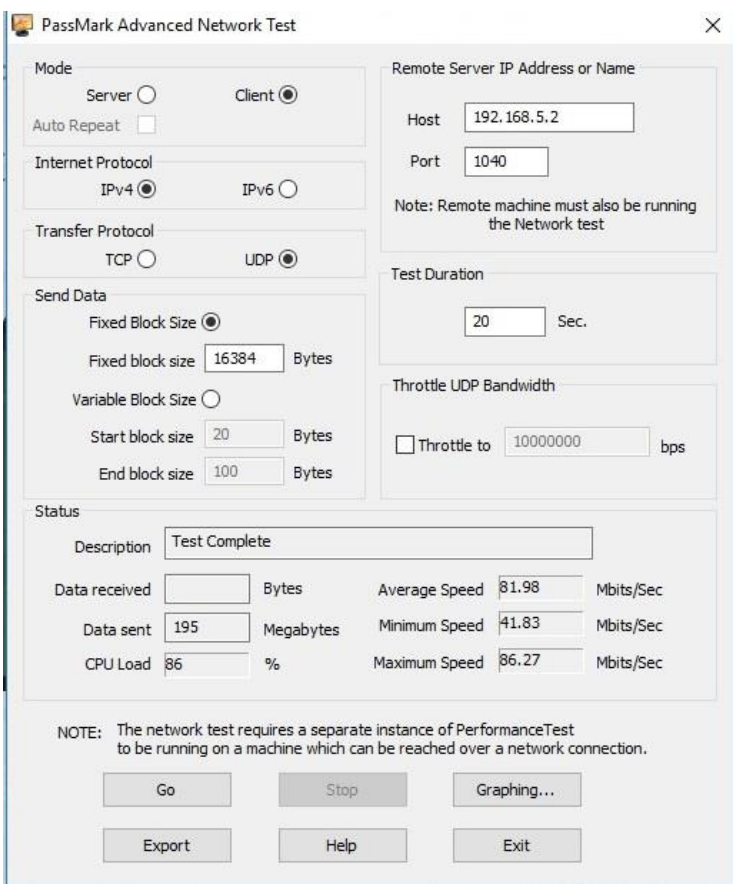

Gambar 4.3 Hasil Pengujian IPv4 dengan Protocol UDP

Gambar 4.3 menunjukan hasil pengujian IPv4 menggunakan protocol UDP dengan mode client dan durasi pengujian 20 detik dan hasil sapat dilihat pada kolom status.

Untuk memudahkan membaca gambar 4.2 dan gambar 4.3 dibuat dalam bentuk tabel sebagai berikut:

Tabel 1. Hasil perbandingan IPv4 pada protocol TCP dan

\begin{tabular}{|l|l|l|}
\multicolumn{2}{c}{ UTP } \\
\hline Data sent & TCP & UDP \\
\hline $\begin{array}{l}\text { Komputer CPU } \\
\text { Load }\end{array}$ & $231 \mathrm{MB}$ & $195 \mathrm{MB}$ \\
\hline Average Speed & $12 \%$ & $86 \%$ \\
& $\begin{array}{l}94,79 \\
\text { Mbits/Sec }\end{array}$ & $\begin{array}{l}81,98 \\
\text { Mbits/Sec }\end{array}$ \\
\hline
\end{tabular}

4.3 Pengujian performa IPv4 pada protocol TCP dan UTP

Pengujian performa IPv4 protocol TCP dan UTP pada gambar dibawah, sebagai berikut: 


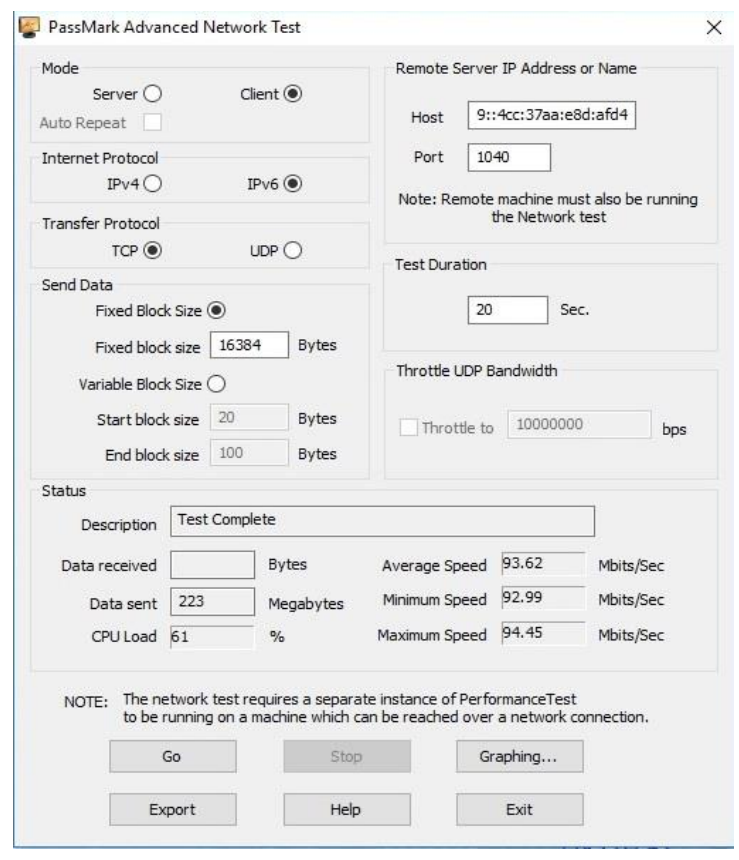

Gambar 4.4 Hasil Pengujian IPv6 dengan Protocol TCP

Gambar 4.4 menunjukan hasil pengujian IPv6 menggunakan protocol TCP dengan mode client dan durasi pengujian 20 detik dan hasil sapat dilihat pada kolom status.

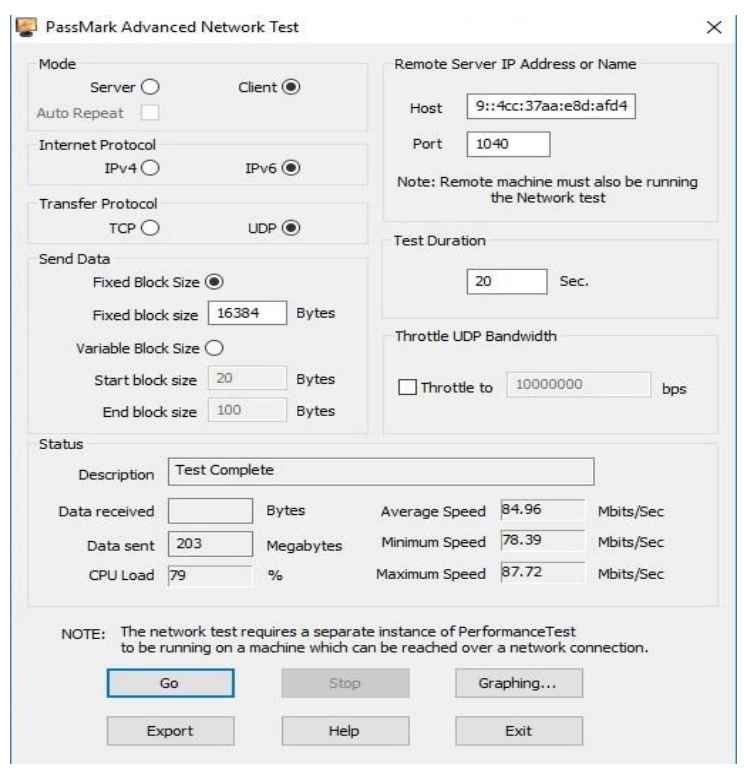

Gambar 4.5 Hasil Pengujian IPv6 dengan Protocol UDP

Gambar 4.5 menunjukan hasil pengujian IPv6 menggunakan protocol UDP dengan mode client dan durasi pengujian 20 detik dan hasil sapat dilihat pada kolom status.
Untuk memudahkan membaca gambar 4.4 dan gambar 4.5 dibuat dalam bentuk tabel sebagai berikut:

Tabel 2. Hasil perbandingan IPv6 pada protocol TCP dan UTP

\begin{tabular}{|l|l|l|}
\hline & TCP & UDP \\
\hline Data sent & $223 \mathrm{MB}$ & $203 \mathrm{MB}$ \\
\hline $\begin{array}{l}\text { Komputer CPU } \\
\text { Load }\end{array}$ & $61 \%$ & $79 \%$ \\
\hline Average Speed & $\begin{array}{l}93,62 \\
\text { Mbits/Sec }\end{array}$ & $\begin{array}{l}84,96 \\
\text { Mbits/Sec }\end{array}$ \\
\hline
\end{tabular}

4.4 Perbandingan performa IPv4 dengan IPv6 pada protocol TCP dan UTP

Hasil perbandingan performa IPv4 dengan IPv6 pada protocol TCP dan UTP ada pada tabel dibawah, sebagai berikut:

Tabel 3. Perbandingan TCP bada IPv4 dan IPv6

\begin{tabular}{|l|l|l|}
\hline & $\begin{array}{l}\text { Hasil TCP } \\
\text { IPv4 }\end{array}$ & $\begin{array}{l}\text { Hasil TCP } \\
\text { IPv6 }\end{array}$ \\
\hline Data sent & $231 \mathrm{MB}$ & $223 \mathrm{MB}$ \\
\hline $\begin{array}{l}\text { Komputer CPU } \\
\text { Load }\end{array}$ & $12 \%$ & $61 \%$ \\
\hline Average Speed & $\begin{array}{l}94,79 \\
\text { Mbits/Sec }\end{array}$ & $\begin{array}{l}93,62 \\
\text { Mbits/Sec }\end{array}$ \\
\hline
\end{tabular}

Pada tabel 3 menunjukan hasil perbandingan TCP bada IPv4 dan IPv6, dilihat dari data sent IPv4 jauh lebih besar data yang dikirim yang artinya IPv4 lebih baik, dilihat dari komputer CPU load yang digunakan jauh lebih kecil pada IPv4 yang aktinya IPv4 lebih baik dan average speed pada IPv4 jauh lebih besar yang artinya IPv4 lebih baik.

Tabel 4. Perbandingan UDP bada IPv4 dan IPv6

\begin{tabular}{|l|l|l|}
\hline & $\begin{array}{l}\text { Hasil UDP } \\
\text { IPv4 }\end{array}$ & $\begin{array}{l}\text { Hasil UDP } \\
\text { IPv6 }\end{array}$ \\
\hline Data sent & $195 \mathrm{MB}$ & $203 \mathrm{MB}$ \\
\hline $\begin{array}{l}\text { Komputer CPU } \\
\text { Load }\end{array}$ & $86 \%$ & $79 \%$ \\
\hline Average Speed & $\begin{array}{l}81,98 \\
\text { Mbits/Sec }\end{array}$ & $\begin{array}{l}84,96 \\
\text { Mbits/Sec }\end{array}$ \\
\hline
\end{tabular}

Pada tabel 4 menunjukan hasil perbandingan UDP bada IPv4 dan IPv6, dilihat dari data sent IPv6 jauh lebih besar data yang dikirim yang artinya IPv6 lebih baik, dilihat dari komputer CPU load yang digunakan jauh lebih kecil pada IPv6 yang aktinya IPv6 lebih baik dan 
average speed pada IPv6 jauh lebih besar yang artinya IPv6 lebih baik.

\section{Kesimpulan dan saran}

Kesimpulan dari penelitian ini dilihat dari protocol TCP pada IPv4 lebih unggul dari pada IPv6 dilihat dari hasil rata-rata data sent, komputer CPU load dan average speed sedangkan pada protocol UDP pada IPv6 lebih unggul dari pada IPv4 dilihat dari hasil rata-rata data sent, komputer CPU load dan average speed.

Saran dari penelitian ini alangkah lebih baik jika dilakukan pengujian ulang dan atau menggunakan software yang berbeda.

\section{Daftar Pustaka:}

[1] Ariyus, Dony,; Andri, R., 2008, Komunikasi Data, Andi, Yogyakarta

[2] Teare, D., 2008, Designing for Cisco Internetwork Solutions (DESGN), Second Edition. Cisco Press, Cisco System Inc

[3] Sugeng, W., 2015, Jaringan Komputer dengan TCP/IP, Modula, Bandung

[4] Sugeng, W., 2006, Jaringan Komputer dengan TCP/IP, Informatika, Bandung

[5] Sofana, I., 2012, CISCO CCNP dan Jaringan Komputer, Informatika, Bandung

[6] Sofana, I., 2013, Membangun Jaringan Komputer, Informatika, Bandung

[7] Yani, A., 2006, Utility Jaringan Panduan Mengoptimalkan Jaringan Komputer Berbasis Windows, PT. Kawan Pustaka Tangerang

[8] Putra, SAP., 2014, Analisis Komparasi QoS IPv4 dan IPv6 pada Topologi Jaringan Komputer di Lab CTC FTI-UKSW, Institutional Repository Universitas Kristen Setya Wacana [Online]. (Diakses http://repository.uksw.edu/handle/123456789/8572, pada tanggal 17 Oktober 2018)
[9] Rahmiati, P,; Aryanta, D,; Priyadi, TA., 2014, Perancangan dan Analisis Perbandingan Implementasi OSPF pada Jaringan IPv4 dan IPv6, Jurnal ELKOMIKA, Institut Teknologi Nasional Bandung, Vol. 2, No.1 Januari Juni, 2014

[10] Ulfa, Maria dan Fatoni., 2017, Analisis Perbandingan Penerapan Static Routing Pada IPv4 dan IPv6, Universitas Bina Darma, Palembang

[11] Wicaksono, A., 2002, Mengenal Format Pengalamatan Host pada Jaringan Komputer Berbasis Protocol IPv6, [Online]. (Diakses http://duktek.if.itb.ac.id/article/prodiif/arti cle/pdf/IPv6.pdf, tanggal 17 Oktober 2018)

[12] Paramayudha, G R., 2010, Analisis Perbandingan Performansi Jaringan IPv6 dan Tunneling 6TO4 Untuk Aplikasi File Transfer Protocol (FTP) Pada Media Wired dan Wireless Disisi Client, Skripsi, Teknik Elektro, Universitas Indonesia

[13] Kalaena, L. S., \& Bagye, W. (2018). Implementasi Network Attached Storage (NAS) Menggunakan Freenas Pada STMIK Lombok. Jurnal Manajemen Informatika dan Sistem Informasi, 1(1), 6-10.

[14] Anonymous, website update pada 11 Maret 2015, Sandi Caesar. wikipedia: https://id.wikipedia.org/wiki/Sandi_Caesar diakses pada tanggal 02 Oktober 2018

[15] Khairul Imtihan. "Perencanaan Strategi Sistem Informasi Pendidikan Pada Sekolah Tinggi Manajemen Informatika dan Komputer (STMIK) Lombok." Bianglala Informatika 3.2 (2015).

[16] Tantoni, Ahmad, Arief Setyanto, and Eko Pramono. "ANALISIS DAN PERANCANGAN BLUEPRINT INFRASTRUKTUR JARINGAN KOMPUTER UNTUK MENDUKUNG IMPLEMENTASI SISTEM INFORMASI PADA STMIK LOMBOK." Informasi Interaktif 3.1 (2018): 67-76. 